\title{
Technological Devices in the Archives: A Policy Analysis
}

\author{
Ciaran B. Trace and Unmil P. Karadkar \\ School of Information, The University of Texas at Austin \\ 1616 Guadalupe St. Austin, TX 78701-1213, USA \\ star@ischool.utexas.edu
}

\begin{abstract}
Doing research in the archive is the cornerstone of humanities scholarship. Various archives institute policies regarding the use of technological devices, such as mobile phones, laptops, and cameras in their reading rooms. Such policies directly affect the scholars as the devices mediate the nature of their interaction with the source materials in terms of capturing, organizing, note taking, and record keeping for future use of found materials. In this paper, we present our analysis of the policies of thirty archives regarding the use of technology in their reading rooms. This policy analysis, along with data from interviews of scholars and archivists, is intended to serve as a basis for developing mobile applications for assisting scholars in their research activities. In this paper we introduce an early prototype of such a mobile application-AMTracker.
\end{abstract}

Keywords: archive reading room, policies, mobile devices, AMTracker.

\section{Introduction}

The conduct of research in the humanities requires an ongoing process of information work. A crucial aspect of this work that is often overlooked are the information management strategies and techniques used by scholars in order to capture, manage, and cite the primary source documents that form a cornerstone of their research. Such strategies and techniques are highly influenced by the conditions that exist in respect to working with archival materials. Archive policies vary widely: while some allow authors to reproduce the source materials through photocopying, scanning, or taking digital images, others prohibit physical or digital reproduction. Such rules have been found to directly affect and disrupt existing research processes and procedures [20].

Given the impact of archive rules and policies on the information gathering practices on scholars, we studied and analyzed the policies related to researchers' use of technological devices in archive reading rooms. Our current policy analysis is limited to the thirty-six archives that participate in TARO (Texas Archival Resources Online), a site that hosts a compilation of collection descriptions (finding aids) for participating archives in the state of Texas. The policy analysis is accompanied by interview data from archivists and scholars to see what impact these rules and policies have on the ground. This analysis serves as a foundation for designing software that will enhance the information management infrastructure available to scholars while conducting research activities in reading rooms. The initial version of the mobile app described here helps 
researchers navigate the culture of the archive by summarizing the policies that scholars can expect to encounter when visiting an archive.

The rest of the paper is organized as follows: we survey related work on the information behavior of humanities scholars, following which we present our analysis of the archives' policies with regard to technology use in the archive. This section is accompanied by additional data from archivists and from scholars gathered as part of in-depth interviews about the information management strategies and techniques of scholars, and the role of the archive in supporting this process. The next section presents AMTracker, a mobile application for easy access to TARO archive policies. We then discuss the of implications of the current policies for designing software to aid scholars in capturing and managing primary source documents while in the archives and conclude with directions for continuing this work.

\section{Related Work}

The study of how humanities scholars conduct research is part of a larger research area that studies the information behavior of various social, economic, and occupational groups. Literature reviews of humanities scholars' information behavior post 1970 [16, 18] found that the work is usually solitary, that scholars use various primary and secondary sources in the research process, adopt different approaches to identify material, use search terms focusing on names of persons and places, browse collections, and that information institutions and professionals are an integral part of the research process.

In the last thirty years, research into the information behavior of humanists has deepened and broadened. One strand of research has studied the research environment including scholars' use of libraries and archives [2, 4, 7, 15], the difference between physical and digital information environments [14], the role of information professionals in the research process, and scholars attitude towards information professionals [7, $8,11,15,18]$. Research has also looked at so-called 'derivative elements' of scholarly work, such as investigating the nature of queries, search terms, and information sources favored by scholars [2, 3, 15]. This work has also further delineated the types of sources that scholars use for data and evidence-noting a strong distinction between primary sources and secondary sources [2, 4, 6, 7, 15, 17]. Research in this vein has also explored topic selection [4] and how researchers search for and locate sources in physical and digital environments [1, 2, 3, 6, 7, 8, 9, 14, 15, 17].

Further research into work process has highlighted the importance of reading and note taking practices to humanities research [2], and shed light on scholars' writing processes and habits [2, 4]. Studies have also highlighted additional steps in the research process, including the strategies and tools that scholars adopt in organizing, naming/labeling, and finding analog and digital information [2, 4, 15]. In recent years, research has shown that the introduction of digital cameras complicates information management practices as researchers struggle to capture, organize, describe, contextualize, and access images subsequent to a research trip [15].

Particularly germane to our study, is research that has examined the forms of knowledge that separate novice from expert users of archives. Two of these forms of 
knowledge-domain (subject) knowledge and artifactual literacy (the ability to interpret and assess records as evidence) — are generally taught within a disciplinary context. The final type of knowledge-archival intelligence (knowledge of archival principles and practices, including "the reasons underlying archival rules and procedures") - relies on the archivist to make this knowledge transparent to patrons [20].

Another area of study directly relevant to our research is that of technology use in the humanities. If, in writing in the early 1980s, Stone [16] felt that it "may be part of the humanistic tradition to be anti-machine" (p. 300), subsequent studies have only served to muddy the waters. Wulf [19], writing in 1995, dismissed the idea of the humanist as technophobe while Massey-Burzio [12] found humanists somewhat ambivalent toward (library) technology in general. Within the past decade research has suggested that humanities scholars have actually "adapted well to rapid technical change," having the ability to "harness information technologies to tried, tested, and somewhat traditional research functions" [2].

Research in this area has also shed light on scholars' preference vis- à-vis material format, the impact of digitization of primary sources and the presence of online finding aids on the research process [1,15], and the importance of copying or capturing archival sources for continued analysis and interpretation $[9,14,15]$. Research suggests that the impact of technology has also been felt within the immediate physical research environment. In 1991, the photocopier was identified as the device that had most affected historical research [4]. Today, that role has been usurped by digital cameras [10] and other scanning equipment [15], and these tools help facilitate the accurate, efficient, and sophisticated copying, sharing, and analysis of primary source material [5]. The use of this equipment is also changing the nature of the work done in the archiveturning archival visits into what has been dubbed "more of a collection mission" [15], with some scholars thinking about offering these images back to the archive to improve access for others [15].

\section{$3 \quad$ Methodology}

We selected archives in the state of Texas for this policy analysis. The TARO Web site (http://www.lib.utexas.edu/taro/) aggregates the finding aids created by thirty-six participating archives in the state and facilitates location of relevant collections by making these available through a unified interface. The Web site enables scholars to browse the finding aids for individual archives or locate information within these finding aids via full-text searches. The TARO interface does not include links to the Web pages that describe the policies of individual archives (although limited policy information can be found in the "Administrative Information" and/or "Restrictions" sections of some of the finding aids). Potential patrons must locate the relevant policies on their own initiative, directly from the archive Web sites.

We visited the individual archive Web sites and located the pages that discuss archive and reading room policies. We reviewed, categorized, and analyzed the policy documents hosted on these archive web sites, focusing on parts that relate to technology use in the archive reading rooms. Each policy page was reviewed by two researchers: 
one recorded and encoded the content from the Web page and a second researcher validated this data. We contextualized our analysis by conducting interviews with a purposeful sample of archive managers who worked for an archive represented in TARO and researchers who have used at least one of these archives. In all, we interviewed three archive managers and four scholars.

To support our objective of eliciting a general overview of the scholars' needs rather than an extensive, deep investigation into the culture of archives themselves, we opted to interview archive administrators representing a small, young academic archive, a large, well-known academic archive, and a public archive. The administrators were all female and each had more than ten years of archival work experience. The administrators are comfortable with using technological devices such as digital cameras, smart phones, tablets, notebook and desktop computers, as well as audio recorders.

We interviewed three female and one male scholar, two of whom are historians, one a media studies researcher, and one a scholar of rhetoric and writing. The scholars were all under the age of 30 and include a post-doctoral scholar, two advanced doctoral students, and a master's student. The scholars possess archival work experience of between one and ten years, each having used at least two archives. Like the administrators, the scholars we interviewed are also comfortable using the technological devices listed above.

\section{$4 \quad$ Findings}

The archives that participate in TARO are managed by institutions with five distinct profiles -25 are academic (public and private), 8 are governmental (state and local), and 3 are private institutions. Of the 36 archives, we located the policies for 30 on their Web sites-23 from academic, 5 from governmental, and 2 from private institutions.

\subsection{Policy documentation on archive web sites}

We studied the found policies, focusing on sections related to the use of recent technological advances (such as laptops, tablets, cameras, phones, and scanners). We found that the archive policies, as well as their placement on the Web pages, varies widely. While some archives display prominent links entitled "Research" or "Policies" that enable potential patrons to locate these, other Web sites bury their policies under sections such as "Collections" or "About". While some archives describe policies concisely on one page, others split the discussion of various policies in multiple sections of the Web site. In some cases, the policies are split in up to six different pages and in various formats, such as HTML, MS-Word, and PDF.

Table 1 illustrates the acceptance of devices at various archives based on the archives' publicly stated policies. We classified the range of acceptance into four categories: policies that clearly mentioned that a device could be used in the reading room (allowed), those that mentioned use with significant caveats (conditional), those that expressly excluded their use in the reading room (disallowed) and those that did not mention the device at all (unknown). The policy documents stated three motivations 
explicitly, although not formally for these policies: the safeguarding of archival materials, ensuring that patron's work does not hinder others' in the reading room, and that the archive gets academic credit or financial remuneration for the use of its materials.

Table 1. TARO Technology Related Policies

\begin{tabular}{c|c|c|c|c|c|c}
\hline & Laptop & Tablet & \multicolumn{2}{c}{ Still } & \multicolumn{2}{c}{ Video } \\
Camera & Camera & $\begin{array}{c}\text { Mobile } \\
\text { Phone }\end{array}$ & Scanner \\
Allowed & 20 & 0 & 13 & 1 & 6 & 1 \\
\hline Conditional & 1 & 0 & 3 & 2 & 0 & 0 \\
\hline Disallowed & 1 & 0 & 3 & 2 & 8 & 13 \\
\hline Unknown & 8 & 30 & 11 & 25 & 16 & 16
\end{tabular}

Our analysis showed that laptops are the most commonly addressed devices; only eight archive policies do not mention them. Next to paper and pencil, laptops are the most accepted form of note taking support for scholars. Most archives that allow laptops expressly require patrons to leave laptop bags in lockers. One archive allows laptops but not "video applications running on laptops". While one policy explicitly disallows devices of any kind, including personal computers, one allows patrons to use them, at the discretion of the archive staff, a situation that we have classified as conditional. While administrators as well as scholars are comfortable using tablets, none of the policies we encountered address this class of devices.

Still cameras rank next to laptops in terms of acceptance with 13 permissive policies. Without exception, these policies prohibit the use of flash. Some policies mention digital cameras, while others restrict the use of professional grade cameras or the use of tripods. Three archives that participate in TARO prohibit the use of cameras altogether and eleven do not mention these devices at all. The three conditional cases include those that permit the use of cameras "at the discretion of the department" or "with consent from a librarian or archivist”.

Among the devices we studied, scholars have used laptops and digital cameras for the longest duration. Therefore, it is somewhat surprising that about a third of the policies do not mention these devices. Mobile phones, video cameras, and personal scanners go unmentioned in at least half of the policies. At the other end of the spectrum, the use of mobile phones and scanners are expressly prohibited in the reading rooms of at least a quarter of the TARO archives.

Notably, scanners or phones are not permitted for use subject to certain conditions. Six policies state that mobile (or cell) phones may be taken into the reading room if they are switched off or silent. Others require that the phones be stowed in lockers provided at the archive. In some archives, it is unclear from the language in the policy whether or not scanners are permitted. Video cameras are the least mentioned devices in the policies, noted by their absence in 25 out of 30 policy documents.

While our analysis of the public documents provides an insight into the spectrum of technology acceptance in the reading rooms it is but one perspective. We complemented this analysis by seeking the views of the archive administrators who define and 
implement such policies as well as those of scholars whose research environment is shaped by these policies.

\subsection{Archive administrators' perspectives}

Prior to the interview, archive administrators completed a questionnaire regarding the devices permitted in the reading room as well as their experiences with devices used by scholars. The responses to these questions clarify the archives' technology related policies. While one archive mentions only that "personal computers" are permitted and another does not mention technology-related issues at all, the administrators' responses indicate that both archives permit the use of all the technological devices listed in table 1 as long as they do not damage the materials or hinder other scholars. The third archive allows mobile/smart phones in the reading room, contradicting the policy documentation on the Web page. The administrators informed us that video cameras, which are not addressed in any of the archives' policies, are disallowed. The administrators also report that scholars increasingly use tablet computers, which the policies notably do not mention, and that reading room staff do not micro-manage the applications that patrons use on permitted devices.

The administrators reported that most of their patrons are experienced researchers and are familiar with the work culture of the archives. It is the administrators' perception that these scholars arrive at the archive prepared with the necessary information to accomplish their objectives. The administrators felt that reading room staff rarely need to answer clarifying questions about policies. Administrators noted that policies are usually changed only when necessitated by patron or staff requests or in response to changes in technology. The current policies at each of the three archives have been in effect for at least three years and the administrators do not expect major policy changes in the near future.

The administrators are supportive of mobile apps as they expect that some features will reduce the burden on archive staff, in addition to aiding patrons. For example, one administrator requested that the app capture metadata about an artifact when the patron takes a picture. Another would like the app to keep track of the relevant materials that scholars have located in the archive.

\subsection{Scholars' perspectives}

In our interviews, scholars indicated that they need help in locating policies as the policies are not always easy to find on archives web sites, and when located scholars sometimes find that the rules are not transparent. The issue is exacerbated by the fact that, as one researcher pointed out, no two archives are the same. Policies differ from institution to institution. Even if the policies are located and understood in one context, the rules do not necessarily transfer or translate to another archive.

The interviews also suggest that scholars are sometimes uncomfortable or unwilling to ask reading room staff about policies. This is partly due to the environment of the reading room where researchers feel that any interaction with the reference staff may 
be disruptive to others working in the space. Researchers try to "fit in" and not make trouble for themselves or the staff.

In addition, we found that researchers characterize what they see as the general culture of the archive, even if they only know the archives by reputation. Part of this characterization comes about through knowing the policies of the archive. Some archives are deemed 'liberal,' 'generous,' or 'open.' While others are deemed 'bureaucratic,' 'picky,' or 'strict.'

Finally, the presence of rules and policies was found to affect researchers directly. This is particularly true in the case of policies that limit the use of personal digital cameras in the reading room. Such a policy may increase the amount of time a researcher spends in an archive, disrupt the preferred method of work process already in place, and result in additional expenses being incurred. As one researcher put it, “... as a grad student your number one priority is not to have any archivist touch anything or do anything for you if you can help it just because it is expensive.”

\section{$5 \quad$ Implications for supporting scholars}

The ever-changing nature of technological devices is not yet reflected in archival policies. For example, policies related to cell phones often treat them as devices for making phone calls or text messaging. Over the last six years, cell phones have evolved from being communication devices alone to being computing and information devices that can run multiple applications, access Web-based content, take high-quality photographs, or record videos. Smartphones now span the spectrum of every device listed in table 1 . How would an archive that allows laptops and still cameras in the reading room but not personal recorders or video cameras determine the status of a smartphone? Tablet computers pose a similar problem. While iPads and Android tablets are commonplace and archivists permit their use in reading rooms, there is not a consensus on whether these should be treated as small personal computers or large mobile phones. As technologies embed themselves in our work lives it becomes increasingly difficult to pry these out of our hands when entering an institution to, well, work some more.

The lack of clear policies related to commonplace devices is challenging from a design perspective as well. Designing applications for use on the most widely used computing platforms is the best strategy for providing meaningful support to a large community of scholars. As archives follow a contingency-based policy-making model, we anticipate that the increasing number of scholars who bring their devices to the archives will eventually lead to crafting of policy statements that cover only these contingencies. However, the danger with this wait-and-watch approach is that the policies crafted may be shaped by the experience of individual archives and an early negative experience may cast a long shadow on permitting the use of an otherwise relevant device or software. Engaging the archive administrators in a discussion early and addressing their concerns head-on as well as designing prototype applications that assist archivists in dispensing their patron-related duties may be a better approach for harnessing the use of technology in scholarly service. 


\subsection{AMTRACKER: MOBILE POLICY INTERFACE}

As a first foray into supporting scholars, we have designed a mobile interface that provides a visual snapshot of TARO archive policies in order to help scholars prepare for an archive visit. Currently, scholars who intend to visit an archive must scour the individual web sites to locate their policies. To complicate matters, policies related to different devices may be stated on different Web pages. Our application, entitled AMTracker, presents a unified view of the device-related policies at each archive. The interface favors simplicity of presentation as well as interaction. The application opens to present an initial view that lists the TARO archives as shown in fig. 1(a). The viewer may scroll through the list and tap on the archive of interest to recall its policies. The policy view is illustrated in fig. 1(b). The interface presents abstract yet familiar graphical icons that represent technological devices such as a laptop, a still camera, and a cell phone. The color of the icon indicates the nature of policies related to the device. We use a color mapping that combines traffic lights and Web conventions: red indicates that the device is disallowed, green indicates that it is permitted, and yellow indicates that the device is permitted with certain caveats (the Conditional category used in table 1). In the case of digital cameras, for example, caveats may include limits on supporting equipment, where and how the technology is used, materials handling rules, quantity limits, copyright restrictions, and fees [13]. Gray icons indicate that the application does not contain a record for policies related to this device. In addition to the devicerelated icons, the interface also contains an icon for the archive's citation policies (the pencil and notepad icon) as well as links to the archive's home page and to its finding aids (Collection Page).

The application employs a client-server architecture and the mobile client retrieves the policy information from a server-side database. While the administrators inform us

\begin{tabular}{l} 
(A) AMTracker \\
\hline African American Library at the \\
Gregory School \\
Alexander Architectural Archive \\
Austin History Center \\
Austin Presbyterian Theological \\
Seminary \\
Benson Latin American Collection \\
Cushing Memorial Library and \\
Archives \\
Daughters of the Republic of \\
Texas Library \\
Dolph Briscoe Center for \\
American History \\
Harry Ransom Humanities \\
Recearrh renter
\end{tabular}

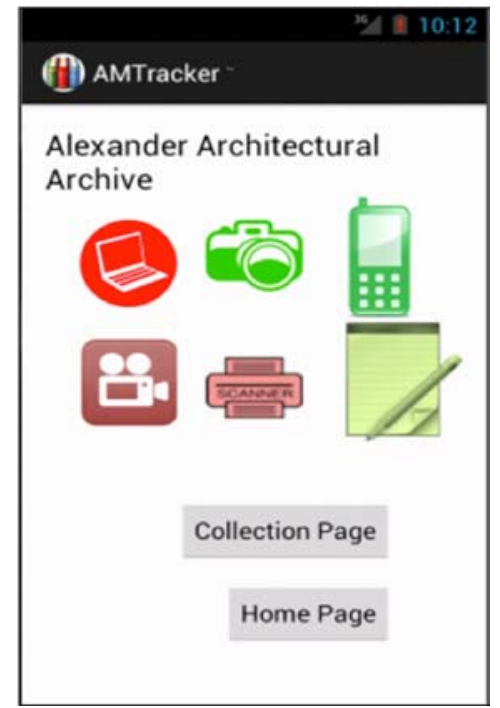

Fig. 1. AMTracker (a) Listing of TARO archives. (b) Policy display 
that the policies do not change frequently, the server-side database will enable us to propagate new policies to all clients when these do change, as well as to include policies for other archives and make these available to all patrons with minimal overhead.

\section{CONCLUSION AND FUTURE WORK}

Our research broadens the examination of scholarly work related to the humanities in the context of supporting work practices in archive reading rooms. Our policy analysis, coupled with administrator interviews, indicates that archive policies continue to evolve and are increasingly welcoming to technological devices, although the public statements sometimes trail the current policies. On the other hand, scholars are eager to adopt technology in order to use their swiftly dwindling resources more efficiently but are hindered by the lack of clarity regarding archive policies as well as the lack of support when using extant technology for scholarly activities.

The cohesiveness of responses among a small sample of archivists and scholars has encouraged us to design technology to support scholarly work practices as well as increase awareness regarding archive policies. Our mobile app, AMTracker, provides scholars with a snapshot of technology acceptance in archive reading rooms. In the next steps of this project, we will deploy the app among the scholars and study its use. In the near term, we expect to study the reading room policies of other significant archives around the world in order to compare the acceptance of technological devices in various countries and cultures. Simultaneously, we are developing features that will enable scholars to contribute details regarding the policies of other archives. This social feature will broaden the utility of AMTracker to scholars who visit archives other than those included in the TARO database. While AMTracker is currently an Android app, we recognize that humanities scholars also use iOS devices. In order to support scholarly practices on different mobile platforms, we are targeting future development toward using a platform-neutral environment, such as Titanium (http://www.appcelerator.com/platform/titanium-platform/).

We continue to explore the needs of scholars and archivists with a view toward introducing technology for improving the scholarly experience as well as for supporting archivists in their tasks. In addition to surveying archivists and scholars, we are designing features that will enable scholars to capture the metadata related to primary source materials and reduce the cognitive overhead in maintaining the primary source materials that are critical for their research.

\section{ACKNOWLEDGMENTS}

This work was supported in part by the School of Information at The University of Texas at Austin through the John P. Commons fellowship. We also thank Xiaowan Wang for her assistance with this project. 


\section{REFERENCES}

1. Anderson, I. G. (2004). Are you being served? Historians and the search for primary sources. Archivaria 58, 81-130.

2. Brockman, W.S., Neumann, L., Palmer, CL., \& Tidline, T.J. (2001). Scholarly Work in the Humanities and the Evolving Information Environment. Washington, D.C.: Digital Library Federation, Council on Library and Information Resources.

3. Buchanan, G., Cunningham, S.J., Blandford, A., Rimmer, J., \& Warwick, C. (2005). Information seeking by humanities scholars. In Andreas Rauber, Stavros Christodoulakis, and A Min Tjoa (Eds.), Proceedings of the 9th European Conference on Research and Advanced Technology for Digital Libraries (ECDL'05) (pp. 218-229). Berlin: Springer-Verlag.

4. Case, D.O. (1991). The collection and use of information by some American historians: A study of motives and methods. The Library Quarterly 61 (1), 61-82.

5. Cox, R.J. (2007). Machines in the archives: Technology and the coming transformation of archival reference. First Monday, 12 (11).

6. Dalton, M.S, \& Charnigo, L. 2004. Historians and their information sources. College \& Research Libraries 65 (5), 400-425.

7. Delgadillo, R., \& Lynch, B.R. (1999). Future historians: Their quest for information. College \& Research Libraries 60 (3), 245-59.

8. Duff, W.M., \& Johnson, C.A. (2002). Accidentally found on purpose: Information-seeking behavior of historians in archives. The Library Quarterly 72 (4), 472-496.

9. Duff, W., Craig, B. \& Cherry. J. (2004). Historians' use of archival sources: Promises and pitfalls of the digital age. The Public Historian. 26 (2), 7-22.

10. Dooley, J. M., Luce, K., \& OCLC Research. (2010). Taking our pulse: The OCLC Research survey of special collections and archives. Dublin, Ohio: OCLC Research.

11. Johnson, C.A., \& Duff, W.M. (2005). Chatting up the archivist: Social capital and the archival researcher. The American Archivist 68 (1), 113-129.

12. Massey-Burzio, V. (1999). The rush to technology: A view from the humanists. Library Trends 47, 620-39.

13. Miller, L., Galbraith. S. K., \& OCLC Research. (2010). “Capture and Release”: Digital Cameras in the Reading Room. Dublin, Ohio: OCLC Research.

14. Rimmer, J., Warwick, C, Blandford, A., Gow, J., \& Buchanan, G. (2008). An examination of the physical and the digital qualities of humanities research. Information Processing and Management 44, 3, 1374-1392.

15. Rutner, J. \& Schonfeld R.C. (2012). Supporting the Changing Research Practices of Historians. Final Report from ITHAKA S+R.

16. Stone, S. (1982). Humanities scholars: Information needs and uses. Journal of Documentation 38 (4), 292-313.

17. Tibbo, H.R. (2003). Primarily history in America: How U.S. historians search for primary materials at the dawn of the digital age. The American Archivist. 66 (1), 9-50.

18. Wiberley, S. E., Jr., \& Jones, W.G. (1989). Patterns of information seeking in the Humanities. College \& Research Libraries 50 (6), 638-45.

19. Wulf, W.A. (1995). Warning: Information technology will transform the university. Issues in Science \& Technology 11, 46-52.

20. Yakel, E. \& Torres, D.A. (2003). AI: Archival intelligence and user expertise. The American Archivist 66, 51-78. 